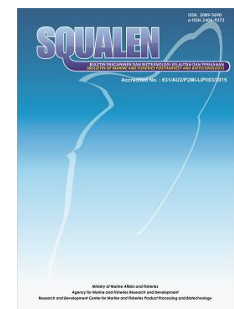

\title{
PURIFICATION AND CHARACTERIZATION OF FUCOIDAN FROM THE BROWN SEAWEED Sargassum binderi sonder
}

\author{
Ellya Sinurat ${ }^{1,2}$; Rosmawaty Peranginangin ${ }^{1}$ dan Endang Saepudin ${ }^{2}$ \\ ${ }^{1}$ Research and Development Center of Marine and Fisheries Product Processing and Biotechnology \\ Jalan KS. Tubun Petamburan VI, Slipi, Central Jakarta 10260, Indonesia; \\ ${ }^{2}$ Department of Chemistry The University of Indonesia \\ Article history: \\ Received: 8 May 2015; Revised: 2 July 2015; Accepted: 23 July 2015
}

\begin{abstract}
The brown seaweed Sargassum sp. is well known as a source of fucoidan. Brown seaweeds found in Indonesia seas are dominated by Sargassum sp. The objectives of this research was to purify and characterize fucoidan from S. binderi Sonder. The fresh raw material was defatted by macerated in methanol:chloroform:water (4:2:1), filtered, rinsed with acetone and then air-dried in room temperature. The defatted dried seaweed was extracted with $0.01 \mathrm{M}$ $\mathrm{HCl} \mathrm{pH} 4$ at room temperature. Purification has been conducted using anion exchanger. The quality of fucoidan sample was determined for total sugar, functional group using FTIR, monomer content, total ash, and total sulfate in the ester form. The result shows that pure fucoidan contains fucose as the primary sugar component, and other minor sugars (galactose, glucose, mannose and xylose). Chemical composition of crude fucoidan consisted of $74.25 \%$ fucose; $0.28 \%$ uronate acid; $10.29 \%$ sulfate and $5.5 \%$ protein. Purification using DEAE Sephadex A-25 gave 4 fraction pools yielding total sugar (\%) of F1 (17.59); F2 (18.92); F3 (13.72); F4 (49.76), respectively. The components that build the fucoidan of $S$. binderi Sonder were estimated derived to be from fucoidan oligomers including $(1,4)$ L-FucS-Gal and D-(1,4)-Gal-GalS.
\end{abstract}

Keywords: fucoidan, Sargassum binderi Sonder, brown seaweed, purification

\section{Introduction}

Indonesian seas are rich sources of a wide variety of brown seaweeds. Widely known brown seaweeds include the genera Sargassum sp., Turbinaria sp., Padina sp. The genus Sargassum sp. particulary consists of hundreds of species and is dominated by Sargassum $s p$ in Indonesia, i.e Sargassum duplicatum, Sargassum crassifolium, Sargassum binderi Sonder (Yunizal., 2006). Brown seaweeds contain a large amount of biologically active polysaccharides, mainly alginate, laminaran and fucoidan which account to 40 to $80 \%$ of dry defatted seaweed biomass. It was previously shown that the content and structures of water-soluble polysaccharides from different sources depend on the habitat and season of harvesting. Fucoidans isolated from brown algae have been extensively studied because of their diverse biological activities such as anticoagulant, antitumor, immunostimulant for fish, anti-virus and anti-inflammatory activities ( $\mathrm{Li}$ et al.,
2008; Isnansetyo et al., 2015; Sinurat et al., 2011). Owing those properties, fucoidans have been investigated in the recent years, as potential candidate drugs and functional foods (Seung-Hong et al., 2012). Fucoidan is a sulfated polysaccharide that is only found in brown seaweed and sea cucumbers ( $\mathrm{Li}$ et al., 2008; Svetlana et al., 2011). Fucoidan is naturally found in two sulfated forms (homo and heterogeneous polysaccharides, in which both are different in sugar composition. The first form is commonly found in sea cucumber, while the latter is found in brown seaweed (Skriptsova et al., 2009). Sugar composition varies among species of brown seaweeds, which usually consists of $(1,3)$ - linked and $(1,4)$ linked L-fucose sulphate as major constituents along with small amounts of uronic acid and other sugars such as galactose, mannose, xylose and glucose (Bilan et al., 2002). The structural characteristics of fucoidan are likely to be dependent on the extraction technique (Ponce et al., 2003; Bilan et al., 2010), seaweed species, harvesting season (Honya., 1999),

${ }^{*}$ Corresponding author.

E-mail: ellya@kkp.go.id 
geographic location (Rioux et al., 2007), and algal maturity (Zvyagintseva et al., 1999). Depolymerizing fucoidan into such oligosaccharides has been achieved by chemical treatment using acid (Harvey, 2011). For enzymatic depolimerazation of fucoidans so far there is no effective enzyme reported (Kusaykin et al., 2008). The sulfated oligosaccharides suitable for mass-spectral investigations were reported for native fucoidan, either by mild acid hydrolysis (Shevchenko et al., 2007) or under solvolytic desulfation conditions (Stanislav et al., 2009).

The content of fucoidan in brown seaweed is influenced by several factors, such as extraction method, growth, season, and species. Those factors affect characteristics and bioactivity of fucoidan (Stanislav et al., 2012). Fucoidan has been recorded from various species and structures. Some notable examples are those from $A$. nodosum that is mainly composed of fucose units by $(1,3)$ and $(1,4)$ bonds (Jung et al., 2010); from Fucus evanescens consist of mainly (1-3)-linked 2-O-sulfonated fucose residues; from Costaria costata from Rusia collected at different life-stages, built up with fucose, mannose and glucuronic acid (Stanislav et al., 2012), and from Sargassum polycystum from Vietnam contains a backbone built up mainly of 3-linked a-L-fucopyranose 4-sulfate residues (Bilan et al., 2013). Additional good example is fucoidan from Undaria pinnatifida from mussel farms at the Marlborough Sounds, New Zealand contained fucose as the primary sugar component followed by galactose, with xylose, glucose and mannose as minor constituents (Mak et al., 2013). This research focused on investigating the characteristics of compounds in the species Sargassum binderi Sonder obtained from Binuangeun (Banten), Indonesia which has not been reported so far.

\section{Material and Methods}

\subsection{Material}

The raw material used in this work was obtained from a brown seaweed Sargassum binderi Sonder collected from Binuangeun. Chemical reagents used include $\mathrm{CaCl}_{2}$ (Merck), ethanol, $\mathrm{CHCl}_{3}$, methanol, $\mathrm{HCl}$, and $\mathrm{H}_{2} \mathrm{SO}_{4}$ p.a. Fucoidan standard from species Fucus vesiculosus was obtained from Sigma Aldrich

\subsection{Methods}

\subsubsection{Extraction}

The fresh brown seaweeds was selected and cleaned from other undesired substances. Briefly, fresh seaweeds were macerated in $\mathrm{MeOH}: \mathrm{CHCl}_{3}: \mathrm{H}_{2} \mathrm{O}$
(4:2:1) for 12 hours to remove fat and pigments, washed with aceton and air dried as illustrated in Figure 1 (modified method of Duarte, 2001). The fucoidan from defatted algal powder was extracted by soaking $0.01 \mathrm{M}$ $\mathrm{HCl}$ of $\mathrm{pH} 4$ at the ratio of 1: $10(\mathrm{w} / \mathrm{v})$, stirred for 6 hours and siefted through a 350 mesh nylon sieve, and added with $4 \mathrm{M} \mathrm{CaCl}_{2}$, incubated for 30 minutes, and re-filtered using 500 mesh. Filtrate was diluted using distillated water until the final $\mathrm{CaCl}_{2}$ concentration of $2 \mathrm{M}$, centrifuged at $15344 \mathrm{~g}$ for 15 minutes, and then added with $3 \mathrm{M} \mathrm{CaCl}_{2}$ and then centrifuged at a speed of $15344 \mathrm{~g}$ for 15 minutes. All polysaccharides were dialyzed (cut off $10.000 \mathrm{Da}$ ) during $48 \mathrm{~h}$ ( 24 hours using $0.5 \mathrm{M} \mathrm{NaCl}$ followed by deionized water for another 24 hours). The sample was precipitated by addition of ethanol (1:2) then left overnight. The fucoidan was analyzed for monosaccharide composition, i.e sulfate, protein and uronic acid. The yield was calculated from the weights of crude fucoidan divided by defatted algal dry weight. The extraction was run in triplicate, and the extraction yield was expressed as mean \pm standard deviation (SD). Each extract was combined and then analyzed.

\subsubsection{Determination of chemical composition of crude fucoidan}

Total sugar content of fucoidan was determined according to Dubois methods using phenol- $\mathrm{H}_{2} \mathrm{SO}_{4}$ reagent using L-fucose (Sigma) as the standard (Dubois, 1956). The sulfate content was quantified based on the $\mathrm{BaCl}_{2}$-gelatin method using $\mathrm{K}_{2} \mathrm{SO}_{4}$ (Merck) as the standard and dehydrolyzed fucoidan as the positive control. Fucoidan sample was hydrolyzed $(15 \mathrm{mg})$ in $3 \mathrm{M} \mathrm{HCl}$ for $17 \mathrm{~h}$ at $100{ }^{\circ} \mathrm{C}$ (Dodgson \& Price, 1962). Uronic acid and protein content of fucoidan were determined using the carbazole-sulphuric acid borate reaction using Dglucuronic acid (Sigma) as standard (Bitter \& Muir, 1962), respectively. All yields were calculated from the dried weight of fucoidan and converted into a percentage. Absorbance measurements were recorded in triplicate using an Ultrospec 2100 UV/ visible spectrophotometer (Thermo Scientific).

\subsubsection{Purification}

Purification of fucoidan was conducted using DEAE Sephadex A-25 and eluted by gradient $\mathrm{NaCl}$ step wise elution (Duarte et al., 2001). Briefly, crude polysaccharides dissolved in $0.1 \mathrm{M}$ buffer Tris- $\mathrm{Cl} \mathrm{pH}$ 7.0 were loaded to a column of DEAE Sephadex A-25 (Sigma Aldrich) fast flow $(4 \mathrm{~cm} \times 25 \mathrm{~cm})$, followed by step-wise elution using $50 \mathrm{ml}$ of sodium chloride solutions $(0.5-2.5 \mathrm{M})$ at the flow rate of $1 \mathrm{ml} / \mathrm{min}$. Eluents ( $5 \mathrm{~mL} / \mathrm{tube}$ ) were separately collected and ethanol (HPLC grade) was added with ratio 1:2. All 


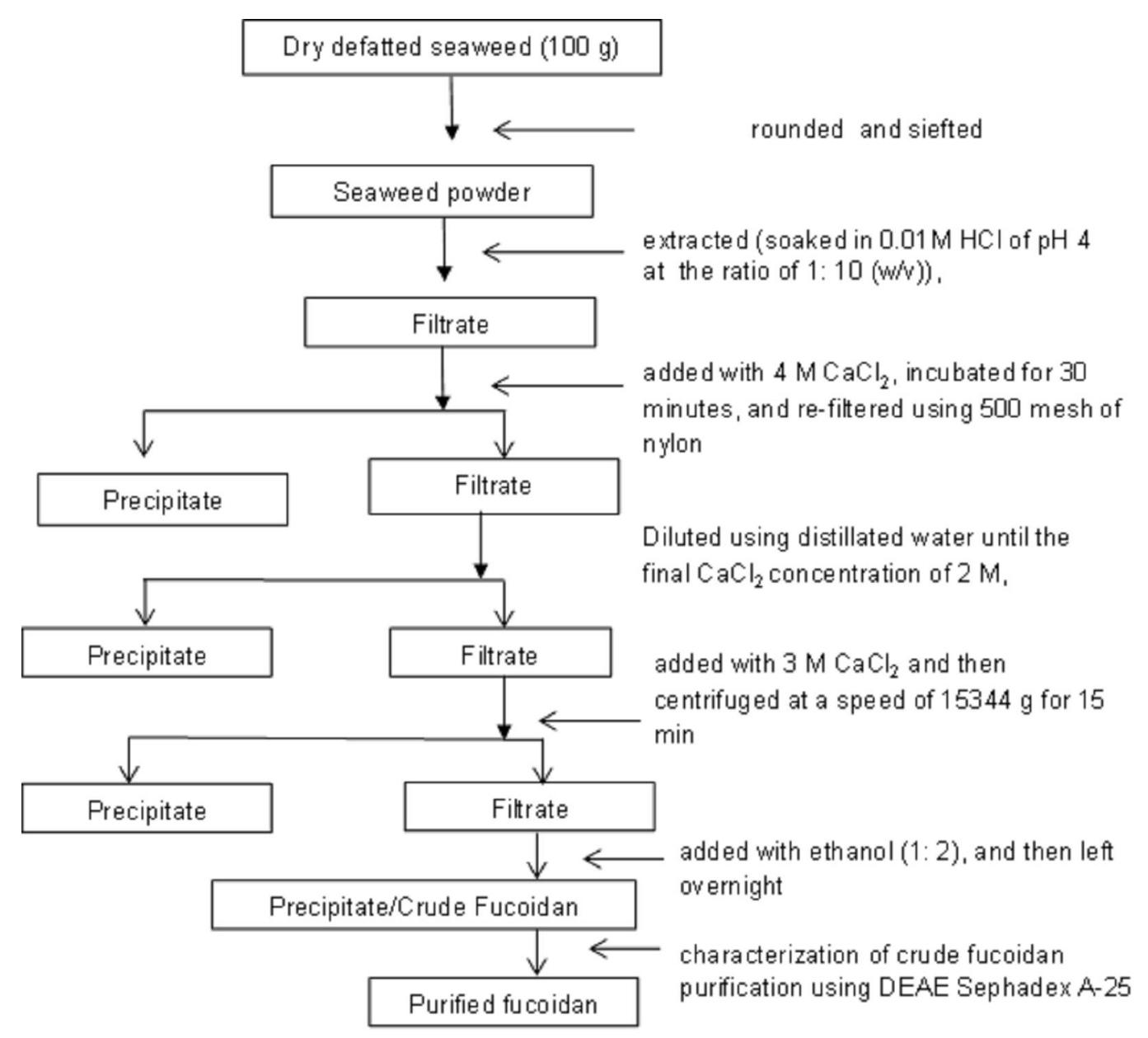

Figure 1. Flow chart of fucoidan extraction and purification.

fractions were filtered, freeze-dried and stored at $4{ }^{\circ} \mathrm{C}$ until used. The carbohydrate content in each eluent was determined using a phenol-sulfuric acid method (Dubois et al., 1956) using fucose (Sigma Aldrich) as the standard. Finally, all the fractions containing polysaccharides were dialyzed with deionized water and lyophilized for further study.

\subsubsection{Sugar composition and methylation analyses of polysaccharides}

Polysaccharides were hydrolyzed with $2 \mathrm{M}$ trifluoroacetic acid (TFA) at $120^{\circ} \mathrm{C}$ for $1 \mathrm{~h}$. After removal of TFA under $\mathrm{N}_{2}$ gas, the hydrolyzates were converted to trimethyl silyl (TMS) using N-Methyl$\mathrm{N}$ (trimethylsilyl) trifluoroacetamide), which were subsequently analyzed by GC using a column HP 5 MS length $(\mathrm{m}) 30 \times 0,25(\mathrm{~mm}) \mathrm{I} . \mathrm{D} \times 0,25 \mu \mathrm{m}$ film thickness. Methylation of polysaccharides was performed according to the Ciucanu's method (Thevis, 2010). Identification of partially methylated TMS was carried out using Agilent 5975C Series GC/MSD on the basis of relative retention time of the standard 1,5di-O-acetyl-2,3,4,6-tetra-O-methyl TMS and the mass fragmentation patterns with several monosaccharides (rhamnose, mannose, fucose, galactose, xylose, and glucose) as the standards.

\subsubsection{Spectroscopic analyses}

IR spectra of polysaccharides sulfates were recorded with Perkin-Elmer 577 ( $\mathrm{KBr}$ pellet) and Specord M-80.

Mass spectrometric analysis. Hydrolysis of fucoidan $(10 \mathrm{mg}$ ) was carried out by mild acid hydrolysis with trifluoroacetic acid $(4 \mathrm{~N}$; $60 \mathrm{~min}$; $121^{\circ} \mathrm{C}, 5 \mathrm{mg} / \mathrm{ml}$ ) in autoclave. The mixtures were neutralized with $5 \% \mathrm{NH}_{4} \mathrm{OH}$ solution and lyophilized. The hydrolytic products were identified by mass spectrometric analysis using LC-QTOF-MS/MS. Spectra were acquired in negative-ion modes with precalibration using a standard "HP-mix". Capillary voltage was set to $4000 \mathrm{~V}$, and the drying gas temperature was $325^{\circ} \mathrm{C}$. Fragmentor voltage was set up to $160 \mathrm{~V}$. 
The isolation window for MS/MS experiments was set up to 1.3 mass units for singly charged ions and 4 mass units for multiply charged ions. Collision energy was optimized between 10 and $45 \mathrm{~V}$ to reach maximum intensity of fragments. Dried sample was dissolved in distilled water at the final concentration of approx. 0.01 $\mathrm{mg} / \mathrm{ml}$, and introduced into the LC-QTOF-MS/MS at flow rate of $2 \mu \mathrm{l} / \mathrm{min}$ in mobile phase (1:1 acetonitrilewater) using a syringe pump (KD Scientific, USA).

\section{Results and Discussion}

The yield of fucoidan crude extracts obtained from Sargassum binderi Sonder was $4.02 \pm 0.27 \%$. Based on the chemical analyses of crude fucoidan, the crude extract contained $74.25 \%$ fucose; $0.28 \%$ uronate acid; $10.29 \%$ sulfate and $5.5 \%$ protein. Chromatographic separation of the crude fucoidan using DEAE Sephadex A-25 resin resulted in 4 fractions as shown in Figure 2. The fractions were individually freeze-dried, yielding of polysaccharides $17.59 \%$ (FP1), 18.9\% (FP2), 13.72 (FP3); 49.76\% (FP4), respectively. FP4 looked more brown physically, indicating that the content of fucoidan in the form of polymer was more dominant (Vishchuk et al., 2011).

GC-MS analyses of the standard fucose TMS and the sample sulfate fucose TMS gave the retention times of 5.752 minutes and 5.823 minutes, respectively. Both monosaccharides exhibited different $\mathrm{m} / \mathrm{z}$ values $(\mathrm{m} / \mathrm{z}$ 73 for the fucose TMS and $\mathrm{m} / \mathrm{z} 204$ for the sulfate fucose TMS). The $\mathrm{m} / \mathrm{z} 73$ in the sample was observed as two adjacent peaks at two slightly different retention time (5.707 minutes and 5.823 minutes). The presence of sulfuric fucose TMS was estimated to elute at 5.823 minutes.

As shown in Figures 3 and 4, there was significant in the fucose TMS spectrum between the crude and the purified fucoidan samples obtained from Sargassum binderi Sonder. The presence of an additional peak (Rt 5.773 minutes) was identified as fucose TMS, which is located next to the fucose sulfate TMS peak (Rt 5.697 minutes). However after purification, such additional peak (fucose TMS) disappeared, leaving only fucose sulfate TMS peak. In addition, detection of high amount of uronic acid in the crude fucoidan was indicated by the high correlation area (19.103). After purification, the correlation area decreased significantly (9.045), suggesting the decreased amount of uronic acid during purification.

GC-MS analyses of the crude fucoidan from Sargassum binderi Sonder indicated the presence of the following monomers: fucose, galactose, glucose, mannose, xylose, and glucuronic acid (abundance ratio of 1:2:7:1:1:4). After purification, the abundance ratio among such monomers became 1:2:4:1:1:2, indicating the decrease of the contaminant glucuronic acid. This result was supported by the decreased correlation area of glucuronic acid as mentioned above, meanwhile GC-MS analyses of commercial fucoidan (Sigma-Aldrich) from Fucus vesiculosus showed the retention times of 5.747 minutes and 5.742 minutes for the fucose TMS and the sample sulfate fucose TMS , respectively (Figure 5). Both monosaccharides exhibited different $\mathrm{m} / \mathrm{z}$ values ( $\mathrm{m} / \mathrm{z} 73$ for the fucose TMS and $\mathrm{m} / \mathrm{z} 204$ for the sulfate fucose TMS).

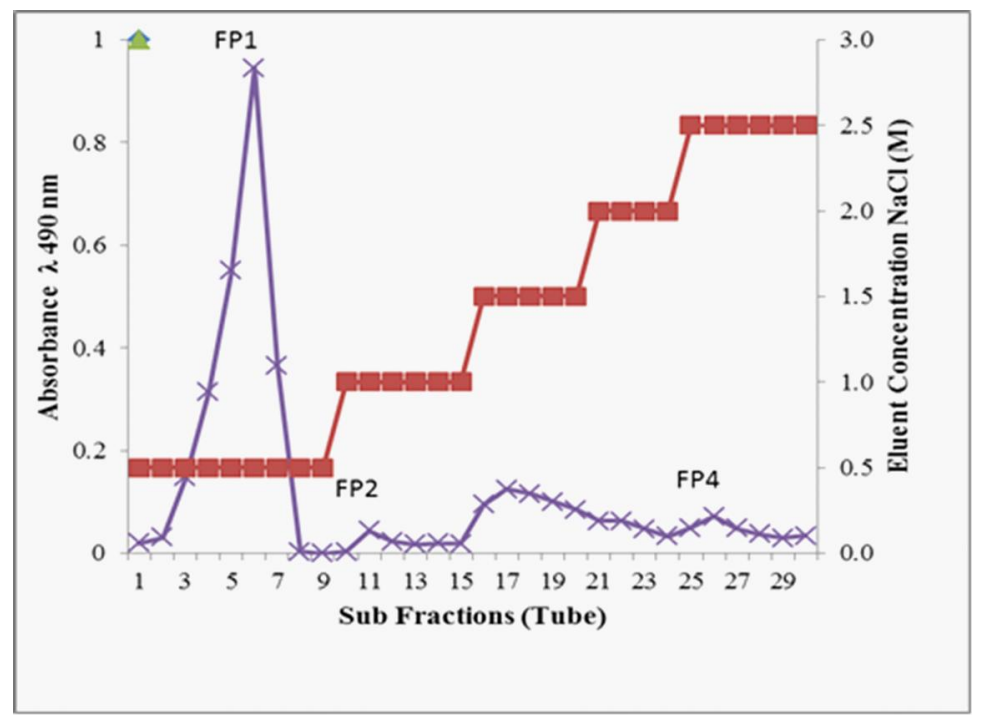

Note: FP1: fraction pool 1 tube 1-9; FP2: fraction pool 2 tube 10-15; FP3: fraction pool 2 tube 16-24; FP4: fraction pool 2 tube 25-30

Figure 2. Purification of fucoidan on Sephadex A-25. 
E. Sinurat, R. Peranginangin, E.Saepudin /Squalen Bull. of Mar. \& Fish. Postharvest \& Biotech. 10 (2) 2015, 79-87

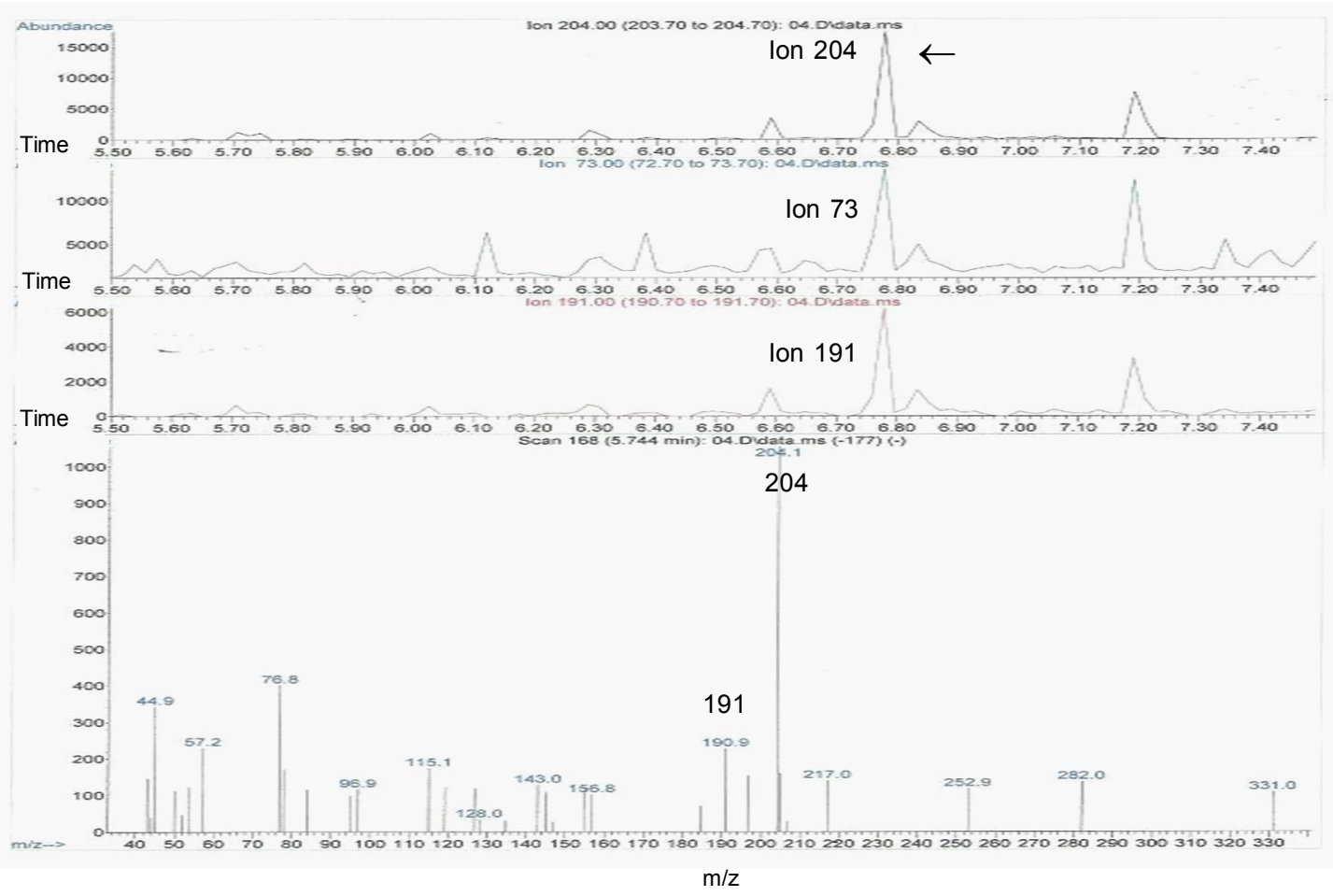

Figure 3. Fucoidan TMS Spectrum from crude Sargassum binderi Sonder.

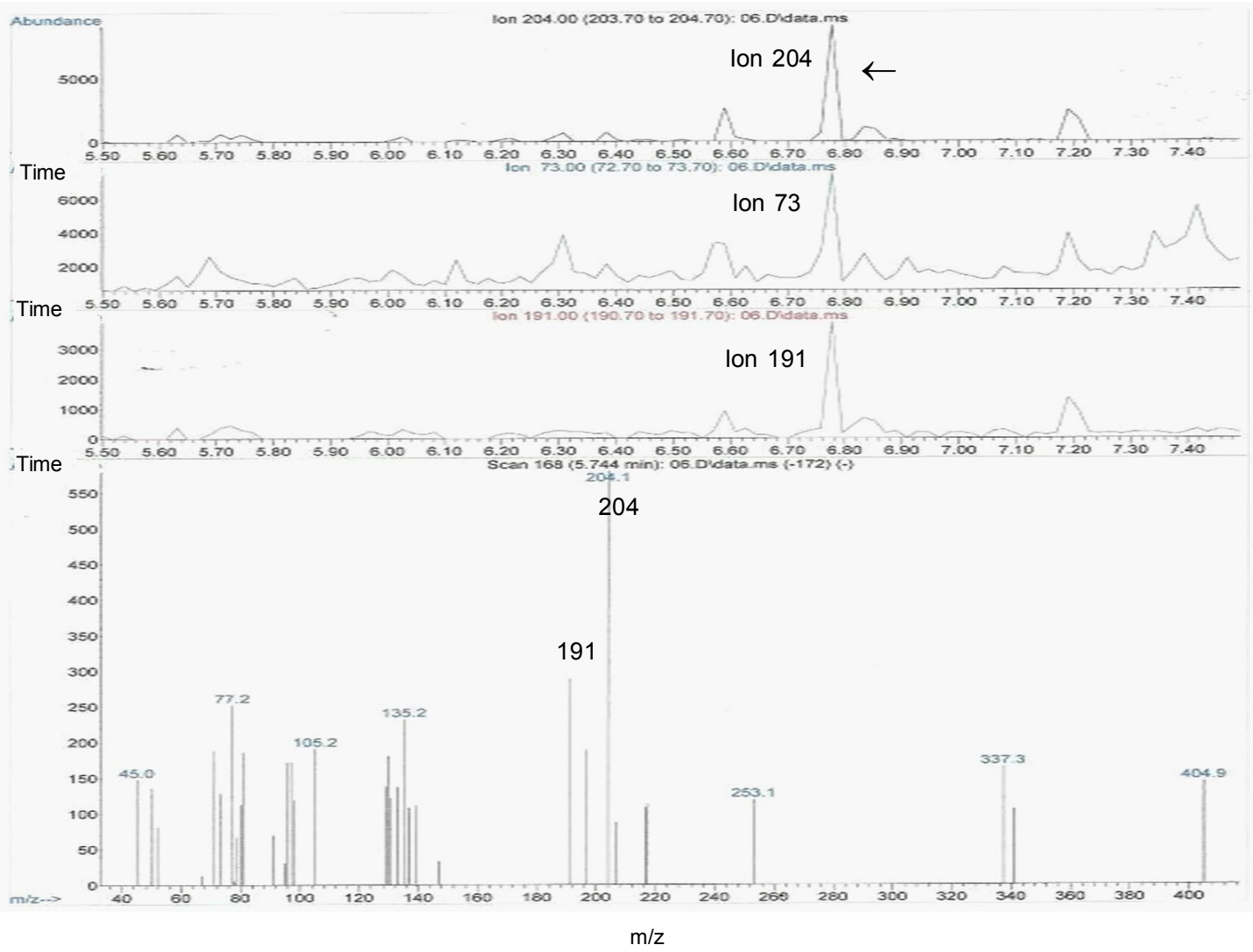

Figure 4. Fucoidan TMS Spectrum from purification Sargassum binderi Sonder. 


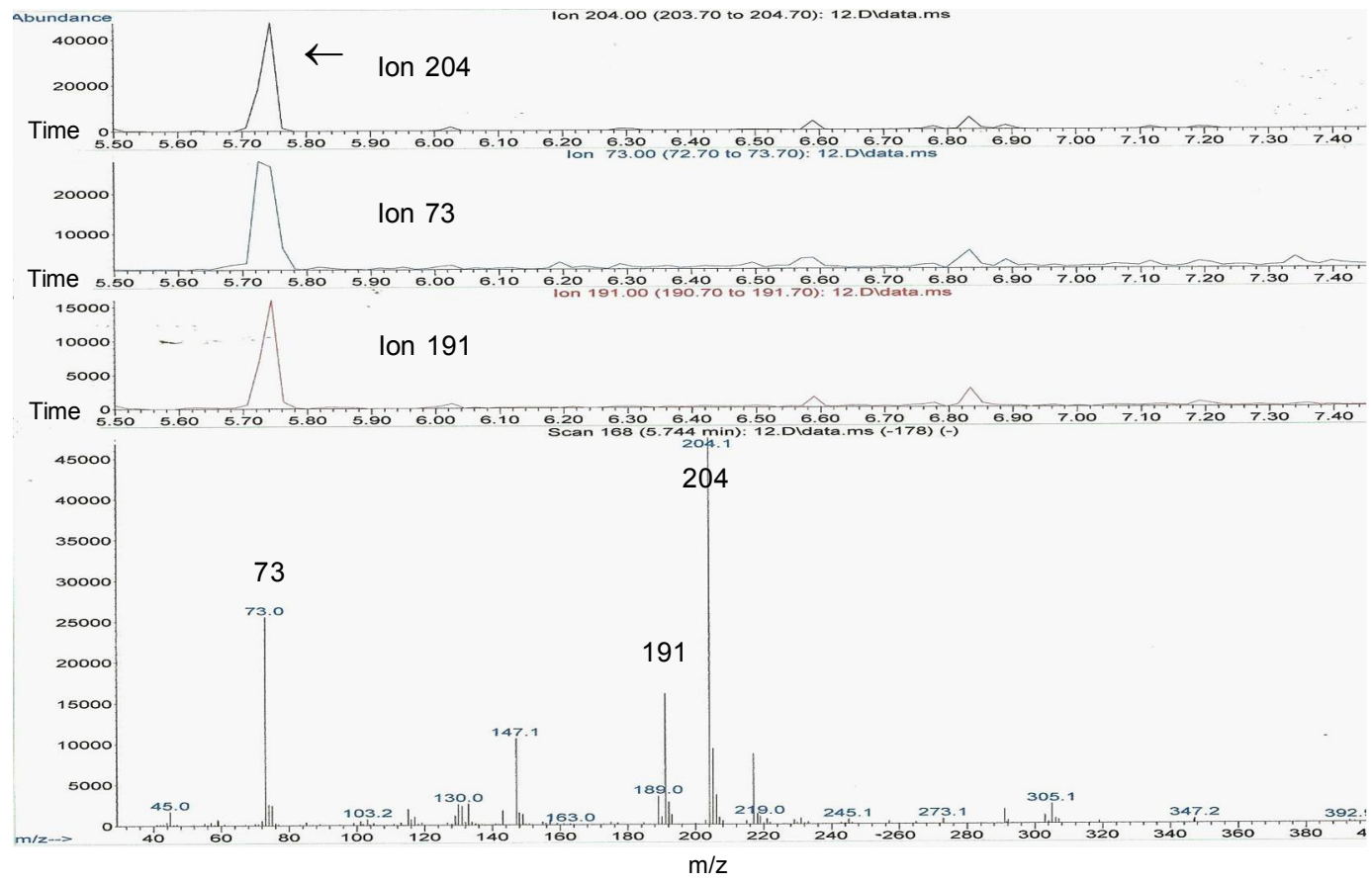

Figure 5. TMS spectrum of Fucoidan from Fucus vesiculosus.

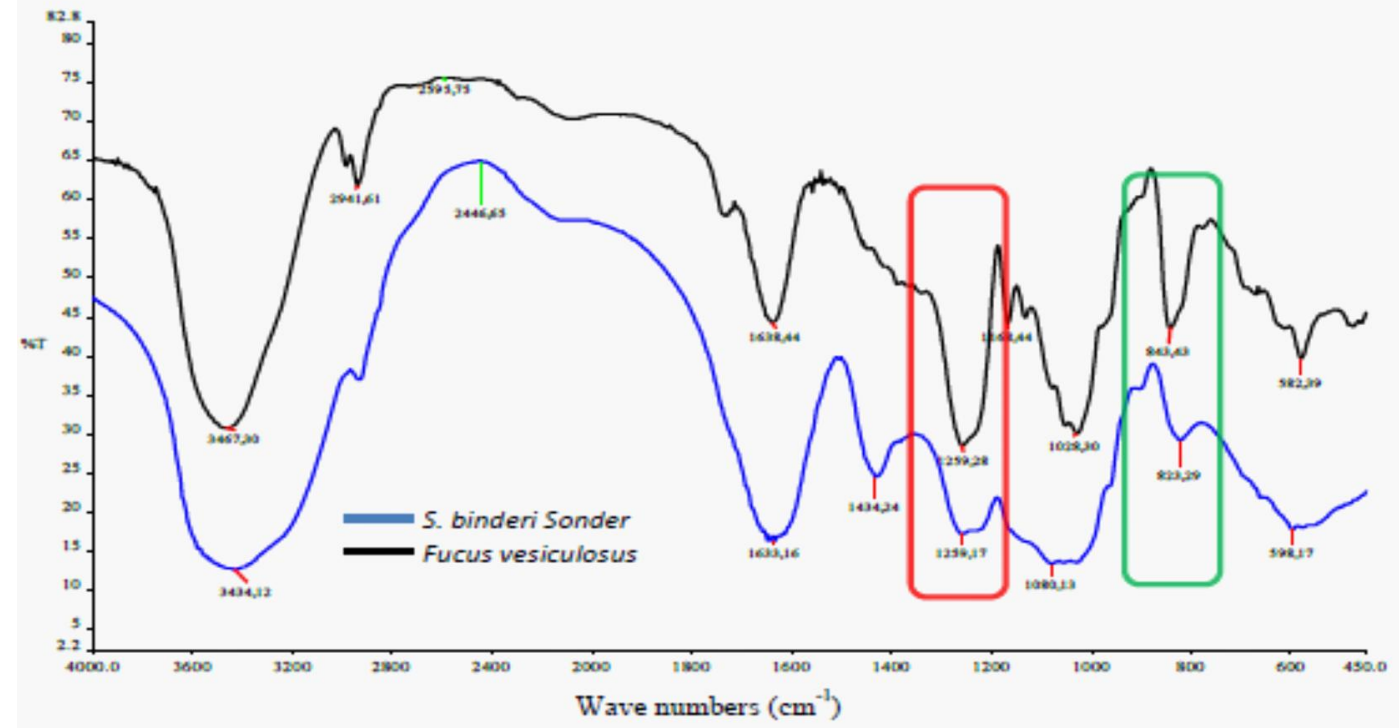

Figure 6. FT-IR spectra of crude fucoidan from Sargassum binderi Sonder and a commercial fucoidan from Fucus vesiculosus.

Based on the FT-IR spectra of the fucoidan (Figure 6), we found absorption at wavenumber of $1259 \mathrm{~cm}^{-1}$ that corresponds to $S=O$ bonds, similar to these in commercial fucoidan (Fucus vesiculosus). It was supported by the appearance of a peak at $823 \mathrm{~cm}^{-1}$ that corresponds to sulfate at equatorial position, assuming that sulfate group binds to the $\mathrm{C}-2$ of fucose to form sulfate fucose, while a commercial fucoidan at $843 \mathrm{~cm}^{-1}$ (Zvyagintseva, et al., 1999; Usov \& Bilan., 2009).
In this work, the negative ion form of sulfated oligosaccharide had been elucidated using LC-QTOFMS/MS. Based on Domon \& Costello (1988), ion [m$\mathrm{Na}]^{\top}$ which $m$ represents changed oligosaccharide was described as the extension of glycosidic cleavage by means of nomenclature. The fragment ions that contain a non-reducing terminus are labeled with uppercase letters $A, B, C$ and the ions that contain the reducing end of the oligosaccharide are labeled with letters $X, Y, Z$. The subscripts indicate the sugar 


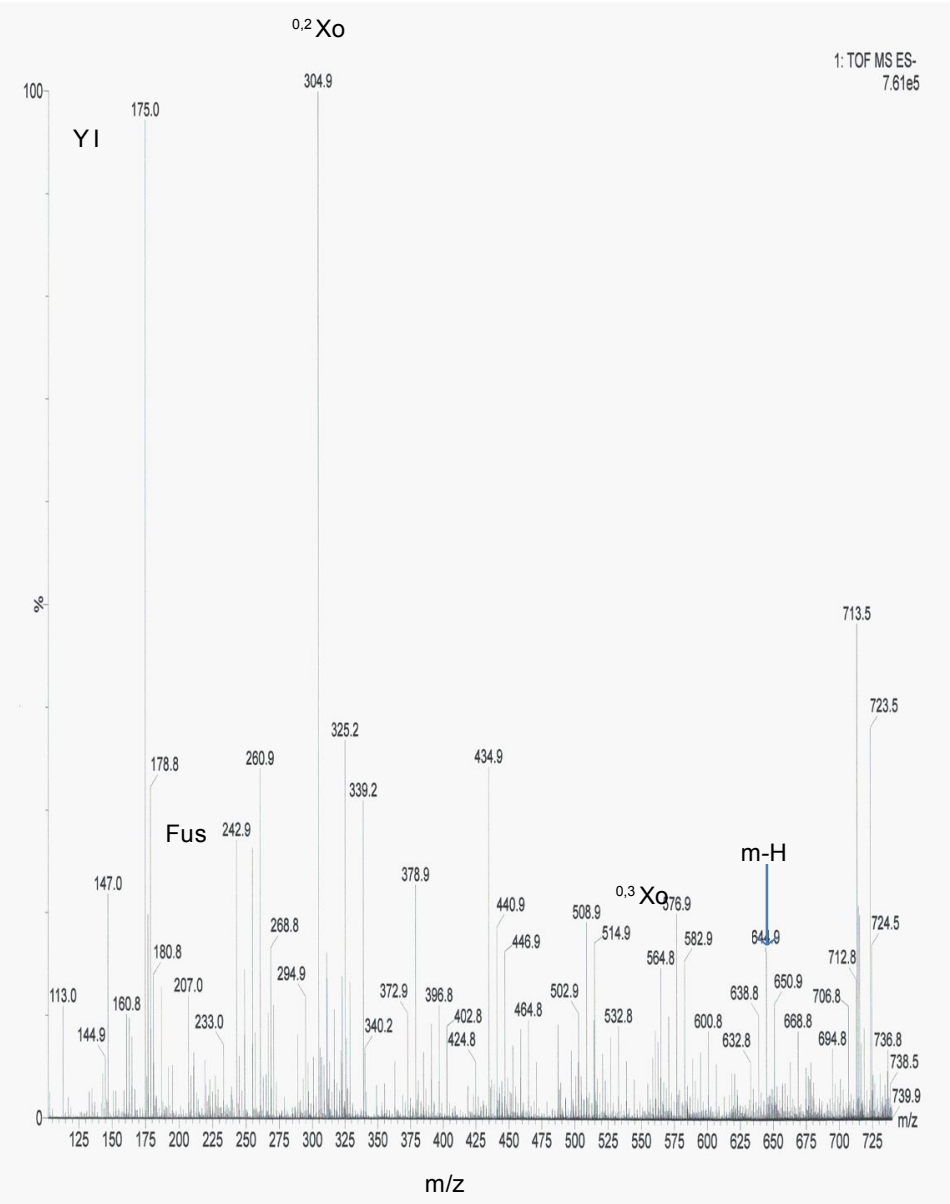

Figure 7. Spectrum of negative ion $\mathrm{m} / \mathrm{z}$ fucoidan Sargassum binderi Sonder.

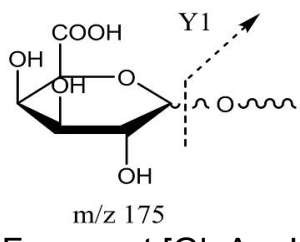

Figure 7A. Fragment [GlcA $-\mathrm{H}_{2} \mathrm{O}^{\urcorner}$

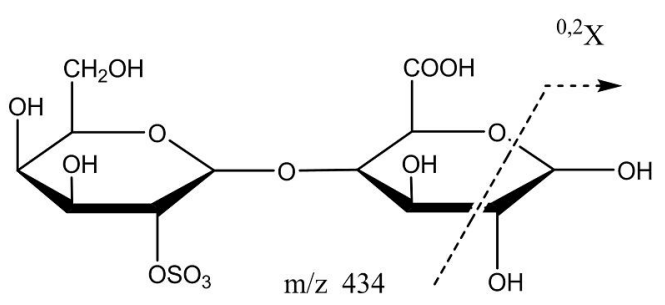

Figure 7C. Fragment ion $\mathrm{m} / \mathrm{z} 434[\mathrm{GalS} \text { GlcA }]^{\urcorner}$

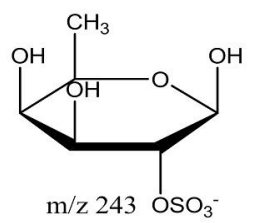

Figure 7B. $\left[\mathrm{Fu} \mathrm{SO}_{3}\right]$ ' sulfated fucose

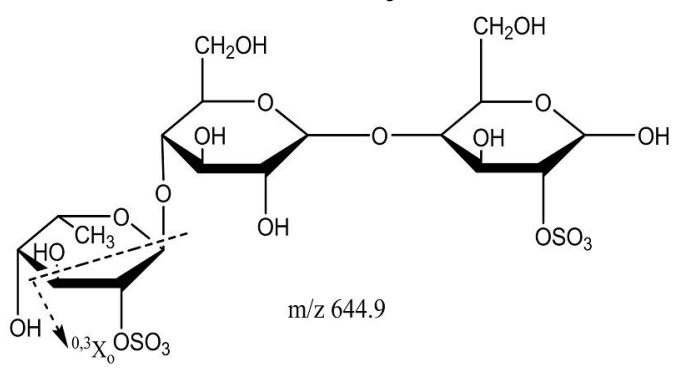

Figure 7D. Fragment ion [FuSGal2S]

Note :[GlcA - $\left.\mathrm{H}_{2} \mathrm{O}\right]^{\urcorner}$glucuronic acid dehydrate; $\left.\left[\mathrm{FucSO}_{3}\right]\right\urcorner$ fucose sulfated; [GaS Glc A] $]^{\urcorner}$sulfated fucose glucuronic acid; [FuSGal2S]' sulfated fucose - sulfated digalactose.

residue numbered from the nonreducing end. $B$ ions are oxonium ions, $\mathrm{Y}$ ions are protonated species that include a $\mathrm{H}$-transfer. $\mathrm{C}$ as protonated molecular ions and $\mathrm{Z}$ ions result from cleavage of glycosidic (Domon \& Costello, 1988; Stanislav et al., 2012; Shevchenko et al., 2015). 
The cleavage of glycosidic bond in the oligosaccharide chain resulted in dehydrated galactose-containing residues ( $\mathrm{Y} 1$ ) marked with $\mathrm{m} / \mathrm{z}$ 175 (Figure 7A) in high intensity. Similar result was also reported for fucoidan from Hizikia fusiforme by Peipei, et al. (2012). The other ion fragment was the sulfated fucose monomer marked at $\mathrm{m} / \mathrm{z}$ of 242.9 (Figure 7B) in medium intensity. Fragment ion forms of fucoidan were observed at $\mathrm{m} / \mathrm{z} 434.9$ in high intensity, which might indicates $(1,4)$ [GalS GIcA]? in Figure 7C. Oligomer forms of fucoidan observed at $\mathrm{m} /$ z 644 were probably [FucSGal2S] '. The chain breakage of [FucSGal2S] ${ }^{\top}$ at ${ }^{0,3} \mathrm{X}$ resulted in $\mathrm{m} / \mathrm{z} 582.9$ and $a t{ }^{0,2} X$ gave $\mathrm{m} / \mathrm{z}$ 304.9. These different ion fragment values indicate the random composition of fucoidan oligomers. Therefore, it was difficult to resolve the repeating pattern of fucoidan oligomers. The ion fragments obtained above suggest that not all fucose contain sulfate groups, as observed for $(1,4)$ [GalGlcA] ' and $(1,4)$ [Fuc2Gal]?.

Fragment ion $\mathrm{m} / \mathrm{z}$ at 644.9 (Figure 7D) contained trisaccharides [FuSGal2S] in medium intensity. The posibble composition of oligosaccharides that builds the structure of fucoidan from Sargassum binderi Sonder included $(1,4)$-L-FucS-Gal and D-(1,4)-GalGalS.

\section{Conclusion}

The yield of crude fucoidan extracted from brown seaweed species Sargassum binderi Sonder was $4.02 \%$. The total fucose and sulfate contents were $74.25 \%$ and $10.90 \%$, respectively. The constituent monomers of crude fucoidan are fucose, galactose, glucose, mannose, xylose, glucuronic acid with a ratio (1:2: $7: 1: 1: 4)$ and after purification, the abundance ratio among such monomers became 1:2:4:1:1:2, indicating the decrease of the contaminant glucuronic acid amount. The estimation building blocks of the fucoidan purified structure include $(1,4)$-L-FucS-Gal and D-(1,4)-Gal-GalS.

\section{Acknowledgements}

This research was financially supported by APBN (National Budget 2015) granted to Ministry of Marine Affairs \& Fisheries Republic of Indonesia. We appreciate Mr. Uria A. for advised grammar and review of this manuscript

\section{Reference}

Bilan Maria I., Alexey A. Grachev, Alexander S. Shashkov, Thanh Thi Thu Thuy, Tran Thi Thanh Van, Bui Minh Ly c, Nikolay E. Nifantiev, Anatolii I. Usov. (2013). Preliminary investigation of a highly sulfated galactofucan fraction isolated from the brown alga
Sargassum polycystum. Carbohydrate Research 377, 48-57.

Bilan, M. I., Grachev, A. A, Ustuzhanina, N. E, Shashkov, A. S, Nifantiev, N. E, \& Usov, A. I. (2002). Structure of fucoidan from the brown seaweed Fucus evanescens. Carbohydrate Research 337,719-730.

Bilan, M. I., Grachev, A. A., Shashkov, A. S., Kelly, M., Sanderson, C. J., Nifantiev, N. E., et al. (2010). Further studies on the composition and structure of a fucoidan preparation from the brown alga Saccharina latissima. Carbohydrate Research, 345(14), 20382047.

Bitter, T., \& Muir, H. M. 1962. A modified uronic acid carbazole reaction. Analytical Biochemistry(4), 330334.

Dodgson, K. S., \& Price, R. G. (1962). A note on the determination of the ester sulphate content of sulphated polysaccharides. Biochemistry, 84, 106110.

Domon B.; Costello C. E., (1988)., A Systematic Nomenclature Carbohydrate Fragmentations in FABMS/MS Spectra of Glycoconjugates. Glycoconjugate J. 5, 397-409.

Duarte, M.; Cardoso, M.; Noseda, M. (2001). Structural studies on fucoidans from the brown seaweed Sargassum stenophyllum. Carbohydrate Research. 333, 281-293.

Dubois, M., Gilles, K. A., Hamilton, J. K., Rebers P. A., \& Smith, F. (1956). Colorimeter method for determination of sugars and related substances. Analytical Chemistry 28, 350-356.

Harvey, D. J. (2011). Analysis of carbohydrates and glycoconjugates by matrix assisted laser desorption/ ionization mass spectrometry: An update for the period 2005-2006. Mass Spectrometry Reviews 30(1), $1-10$.

Honya, M., Mori H., Anzai, M., Araki and Nisizaa, K., 1999., Monthly Changes in the Content of Fucans, Their Constituent Sugars and Sulphate in Cultured Laminaria japonica. Hydrobiologia. 398/399, 411416.

Isnansetyo A., A. Fikriyah N., Kasanah., Murwantoko. (2015). Non-specific immune potentiating activity of fucoidan from a tropical brown algae (Phaeophyceae), Sargassum cristaefolium in tilapia (Oreochromis niloticus). Aquaculture International. DOI 10.1007/s10499-015-9938-z.

Jung Z., Takasi Okimura, Takeshi Yokose, Yasuhiro Yamasaki, Kenichi Yamaguchi and Tatsuya Oda. (2010). Effects of sulfated fucan ascophyllan from the brown Alga Ascophyllum nodosum on various cell lines: A comparative study on ascophyllan and fucoidan. Journal of Bioscience and Bioengineering 110 (1), 113-118.

Kusaykin M, Bakunina I, Sova V, Ermakova S, Kuznetsova T, Besednova N, Zaporozhets T, Zvyagintseva T. (2008). Structure, biological activity, and enzymatic transformation of fucoidans from the brown seaweeds. Biotechnol J.3,904-915 
Li, Bo.; Lu Rui, X.Z.; Xin, J.W. (2008). Anticoagulant activity of fucoidan from Hizikia fusiforme. Agro Food Ind. Hi-tech. 19, 22-24.

Mak, W. N. Hamida, T. Liua, J. Lu, W.L. White. (2013). Fucoidan from New Zealand Undaria pinnatifida: Monthly variations and determination of antioxidant activities. Carbohydrate Polymers 95, 606- 614

Peipei W., Xialiang Zhao, Youjing Lv, Yanan Liu, Yinzhi Lang, Jiandong Wu, Xin Liu, Miaomia Li, Guangli Yu. (2012). Analysis of Structural heterogeneity of Fucoidan from Hizikia fusiforme by ES-CID-MS/MS. Carbohydrate Polymers 90, 602-607.

Ponce, N. M., Pujol, C. A., Damonte, E. B., Flores, M. L., \& Stortz, C. A. (2003). Fucoidans from the brown seaweed Adenocystis utricularis: Extraction methods, antiviral activity and structural studies. Carbohydrate Research, 338, 153-165.

Rioux, L. E., Turgeon, S. L., \& Beaulieu, M. (2007). Characterization of polysaccharides extracted from brown seaweeds. Carbohydrate Polymers 69,530537.

Seung-Hong L., Lee SH, Park MH. (2012). Deckle isolated from Ecklonia cava protects against high glucose in duced damage to rat insulinoma cells by reducing oxidative stress and apoptosis. Biosci Biotechnol Biochemistry, 76(8):1445-51.

Shenchenko N.M. (2007). Polysaccharide and lipid composition of the Brown seaweed Laminaria gurjanovae. Russian journal of Bioorganic chemistry. ISSN 1068. Vol.33. (1), 96-107.

ShevcenkoN. M., Anastyuk, S. D., Gerasimenko, N. I. Dmitrenok, P. S., Isakov, V. V., \& Zvyagintseva, T. N. (2007). Polysaccharide and lipid composition of the brown seaweed Laminaria gurjanovae. Russian Journal of Bioorganic Chemistry, 33(1), 88-98.

Shevchenko, N. M., Anastyuk, S. D., Roza V. Menshova., Olesya S. Vishchuk, Vladimir I. Isakov, Pavel A. Zadorozhny, Tatiana V. Sikorskaya, Tatiana N. Zvyagintseva. (2015). Further studies on structure of fucoidan from brown alga Saccharina gurjanovae. Carbohydrate Polymers 121, 207-216

Sinurat, E., Rosmawaty, P., dan Saepudin, E. (2011). Ekstraksi dan Uji Aktivitas Fukoidan dari Rumput Laut Coklat (Sargassum crassifolium) sebagai Antikoagulan. Jurnal Pascapanen dan Bioteknologi Kelautan dan Perikanan. 6(2), 131-138.

Skriptsova, A. V., Shevchenko, N. M., Zvyagintseva, T. N., \& Imbs, T. I. (2009). Monthly changes in the content and monosaccharide composition of fucoidan from
Undaria pinnatifida (Laminariales, Phaeophyta). Journal of Applied Phycology 22,79-86.

Stanislav D. Anastyuk, Natalia M. Shevchenko, Evgeny L. Nazarenko, Pavel S. Dmitrenok, Tatyana N. Zvyagintseva (2009). Structure analysis of a fucoidan from the brown alga Fucus evanescens by MALDITOF and tandem ESI mass spectrometry. Carbohydrate research 344, 779-787.

Stanislav D. Anastyuk, Natalia M. Shevchenko, Svetlana P. Ermakova, Olesya S. Vishchuk, Evgeny L. Nazarenko, Pavel S. Dmitrenok, Tatyana N. Zvyagintseva. (2012). Anticancer activity in vitro of a fucoidan from the brown alga Fucus evanescens and its low-molecular fragments, structurally characterized by tandem mass-spectrometry. Carbohydrate Polymers 87, 186- 194.

Svetlana E. \& Roza Sokolova \& Sang-Min Kim \& ByungHun Um \& Vladimir Isakov \& Tatyana Zvyagintseva. (2011). Fucoidans from Brown Seaweeds Sargassum hornery, Eclonia cava, Costaria costata: Structural Characteristics and Anticancer Activity. Appl Biochem Biotechnol 164, 841-850

Synytsya A., Kim, W. J., Kim, S. M., Pohl, R., Synytsya, A., Kvasnicka, F. (2010). Structure and antitumor activity of fucoidan isolated from sporophyll of Korean brown seaweed Undaria pinnatifida. Carbohydrate Polymers 81, 41-48.

Thevis M. (2010). Mass Spectrometry in Sports Drug Testing: Characterization of Prohibited Substances and Doping Control Analytical Assays., John Wiley \& Sons, Volume 49 dari Wiley Series on Mass Spectrometry. ISBN:1118035143, 9781118035146; $360 \mathrm{p}$

Usov A.I and Bilan M.I. (2009). Fucoidan -sulfated polysaccharides of brown algae. Russian chemical reviews 78(8), 785-799.

Vishchuk O. S., Ermakova, S. P., \& Zvyagintseva, T. N. 2011. Sulfated polysaccharides from brown seaweeds Saccharina japonica and Undaria pinnatifida: isolation, structural characteristics, and antitumor activity. Carbohydrate Research, 346, 2769-2776.

Yunizal. (2004). Teknologi Pengolahan Alginat., Pusat Riset Pengolahan Produk dan Sosial Ekonomi Kelautan dan Perikanan. Jakarta. ISBN 979-97355, 6-12

Zvyagintseva, T. N., Shevchenko, N. M., \& Popovnich, I. B. (1999). A new procedure for the separation of watersoluble polysaccharides from brown seaweeds. Carbohydrate Research, 322, 32-39. 